\title{
REFLEXIONES Y PRECISIONES SOBRE EL ORIGEN Y LA DIFUSIÓN DE LAS CUSTODIAS DE SOL CON ÁGUILA BICÉFALA
}

\author{
REFLECTIONS AND PRECISIONS ON THE ORIGIN AND \\ THE DIFFUSION OF THE SUN MONSTRANCES WITH \\ DOUBLE-HEADED EAGLE
}

\author{
Carmen Heredia Moreno \\ Universidad de Alcalá. España \\ ORCID: 0000-0002-2225-9107 \\ carmen.heredia@uah.es
}

\begin{abstract}
A partir de un detallado análisis del estado de la cuestión, se hace un minucioso estudio del origen y difusión de la iconografía del águila bicéfala en las custodias de sol precisando o rectificando algunas cuestiones. Se añade una nueva pieza al grupo, se reafirma sustancialmente la tesis planteada en el año 1996 y se rebaten la mayoría de las opiniones, contrarias a dicha tesis, que se publicaron en el 2017.

Palabras clave: custodia de sol; águila bicéfala; fuentes gráficas.
\end{abstract}

From a detailed analysis of the state of the question, the paper does a meticulous study of the origin and diffusion of the iconography of the double-headed eagle in the sun monstrances, needing or rectifying some questions. A new piece is added to the group, the thesis raised in 1996 is reaffirmed substantially and the most opinions published in the 2017, opposite to this thesis, are refuted.

Keywords: sun monstrance; double-headed eagle; graphics sources.

En España se conserva un interesante grupo de custodias de sol, labradas durante la segunda mitad del siglo XVII y los comienzos del XVIII, cuyo denominador común es que todas tienen un águila bicéfala en el astil como parte integrante de su estructura. En 1996 se estableció el origen de esta iconografía en un grabado de María Antonia Beer del año 1640, inserto en el Sumo Sacramento de 
la Fe escrito por el jesuita Francisco Aguado ${ }^{1}$. Pero esta tesis ha sido puesta en duda en los últimos años ${ }^{2}$. Al hilo de estas diferencias de criterio, nuestro objetivo consiste ahora en hacer una minuciosa revisión del tema para confirmar, precisar $\mathrm{o}$, en su caso, rectificar algunos aspectos sobre el origen y la difusión del modelo.

Según el actual estado de la cuestión, la primera custodia que se dio a conocer fue la de Alquézar (Huesca) (60 cm de alto), descrita en 1921 como: "La custodia, de rayos, de plata sobredorada ostenta en su nudo un águila bicéfala explayada" ${ }^{3}$. Años más tarde, Ezquíroz la clasificó en el siglo XVII como obra de taller oscense o cortesano e indicó que la reliquia albergada en el pecho del águila pudo ser una de las que donó el licenciado Bartolomé de Lecina, canónigo de Milán, que pasó a Alemania en 1580 en compañía del duque de Terranova, embajador de Felipe II. De igual forma, apuntó la posibilidad de que la custodia hubiese llegado a la parroquia por donación de la familia Nasarre, ya que algunos de sus miembros procedían de Alquézar y contaron con vínculos cortesanos durante los reinados de Carlos II y de Felipe V 4 .

Otra obra parecida a la anterior (64 $\mathrm{cm}$ de alto), de plata dorada, con la decoración reducida a la figura del águila y a las estrellas del sol, se descubrió en la parroquia de San Martín de Cartes (Cantabria). Su inscripción en el borde del pie, "RAIFELPE 1680", establece con exactitud su fecha de realización, aunque no su lugar de origen que se consideró, con reservas, castellano o madrileño ${ }^{5}$.

En Salamanca y su provincia se conservan tres piezas con la misma iconografía. Gómez Moreno reprodujo la del convento de Agustinas de la ciudad de Salamanca, obra de la segunda mitad del siglo XVII, de plata sobredorada repujada, con perlas y piedras preciosas. Madruga Real la describiría más tarde de forma detallada indicando que "El receptáculo para la Sagrada Forma es el centro de una gran flor abierta de ocho pétalos en cuyos centros van las letras de Monterrey pintadas; sobre ella una corona con la cruz y debajo una gran águila bicéfala con la imagen de la Inmaculada pintada en el centro; se apoya sobre pedestal de 3 caras, en el que aparecen los retratos, pintados, de Juan Domingo de Haro e Inés de Zúñiga, quienes regalaron la obra al convento" ${ }^{6}$. Por su parte, Pérez Hernández concretó su cronología al final del siglo XVII, mencionó sus esmaltes traslúcidos y la interpretó como una exaltación de la Eucaristía y de su propio linaje, al que

${ }^{1}$ Heredia Moreno, 1996: 183-194.

2 Sigaut, 2017: 70-92.

3 Arco y Garay, 1921: 100.

${ }^{4}$ Esquíroz Matilla, sin fecha: $n^{\circ}$. cat. 600. Esquíroz Matilla, 1994, inédito. Mi sincero agradecimiento a la doctora Esquíroz por su amabilidad al comunicarme personalmente todos estos datos.

${ }^{5}$ Carretero Rebes, 1986: 105.

${ }^{6}$ Madruga Real, 1983: 135-136. 
se aludía en los retratos y en la leyenda "MONTEREI" clasificó la del convento de Carmelitas de Alba de Tormes ( $79^{\prime} 7 \mathrm{~cm}$ de alto), de plata dorada y esmaltes, como obra madrileña del último tercio del XVII y transcribió su inscripción "SEÑOR INES SIEMPRE A TUS PIES" ${ }^{8}$. La pieza más tardía de todo el grupo es el expositor del Museo Diocesano (140 cm de alto), de plata parcialmente dorada, en forma de gran águila bicéfala coronada, con el viril de oro en el pecho9. Esta obra fue labrada por el artífice salmantino Manuel García Crespo a mediados del siglo XVIII y ostenta su punzón MANUE/GARZA y el de Francisco de Villarroel, VILLA/ROEL, que fue marcador municipal entre 1707 y $1749^{10}$.

La Exposición Iberoamericana de Sevilla dio a conocer la custodia del cabildo Catedral de Madrid, hoy en paradero desconocido, que se consideró una obra del siglo XVII, si bien en la de Orfebrería y Ropas de Culto se afirmó que estaba fechada en $1712^{11}$. Por su parte, el Catálogo Monumental de Navarra recogió la de la parroquia de Valtierra $\left(70^{\prime} 5 \mathrm{~cm}\right.$ de alto), de plata dorada, oro y piedras preciosas, indicando que fue labrada en torno a 1700 por el artífice Cristóbal de Alfaro, miembro de una dinastía de plateros navarros establecidos en la Corte ${ }^{12}$. La señal del contraste y marcador de villa Juan Muñoz, según la variante JU/ MUÑOZ, permitió ajustar su cronología entre 1695 y $1712^{13}$. Aranda Huete documentó que los patronos de la parroquia navarra hicieron el encargo en el año 1699 y que el artífice ya había realizado cuatro coronas de plata para las imágenes de la Virgen de la Esperanza, del Rosario y de sus Niños antes de $1693^{14}$.

7 Pérez Hernández, 1990: 189.

8 Pérez Hernández, 1990: 189.

9 Rodríguez G. de Ceballos, 1969.

${ }_{10}$ Pérez Hernández, 1990: 300 y 45.

${ }_{11}$ Exposición Iberoamericana, 1930: Sala I, nº 185. Camps Cazorla, Emilio, 1941: 83.

12 Se publicó en García Gaínza/Heredia Moreno/Rivas Carmona/ Orbe Sivatte, 1980: 412. Según nota al margen de un documento del Archivo parroquial de Valtierra fue la pieza de examen de Cristóbal de Alfaro, natural de la villa navarra.

${ }_{13}$ Heredia Moreno, 1996: 187. Martín, 1987: 383.

${ }^{14}$ Aranda Huete, 1999: 253-254. Descarta que la custodia sea una pieza de examen, por su gran envergadura impropia de esta prueba, y porque Alfaro era platero de oro y no estaba cualificado para labrar obras de plata. Por ello sugiere que Alfaro sólo compró la custodia que pudo confeccionarla su colega y amigo Juan Muñoz o cualquier otro artífice madrileño. Sin descartar por completo esta tesis y teniendo en cuenta también que la nota del documento podría ser añadida, recordemos que el platero ya había confeccionado varias piezas de plata para su villa natal y que la parroquia navarra encargó la custodia al propio Alfaro. Además, aunque, efectivamente, las piezas de examen solían ser más senci1las, García Gaínza, 1991: 102, recogió el dibujo de una custodia que fue la pieza de examen del platero Luis Sanz en el año 1722. Por último, tengamos en cuenta que Juan Muñoz era marcador municipal en el año 1699 y no es probable que fuese marcador y artífice de 
En cuanto a la custodia de Orduña (Vizcaya) ( $87 \mathrm{~cm}$ de alto), de plata sobredorada con sobrepuestos de pedrería en las plumas, corona y estrellas, la pieza está documentada por su expresiva inscripción que informa que "Esta cvstodia es de la yglesia de Santa Maria de la civdad de Hordvña. mandola hacer a sv costa i la dio de limosna el capitan don Antonio de Odiaga y Lezama. Año de 1683. Egecvtola Rafael Gonçales Sobera, platero del Rei"15.

Por último, en el mismo grupo se incluye la del Museo de Arte Arquidiocesano de Popayán ( $96^{\prime} 5 \mathrm{~cm}$ de alto), de plata dorada con perlas, amatistas y vidrios de colores ${ }^{16}$. Según Fajardo Rueda, fue labrada por los artífices locales Antonio Rodríguez y N. Álvarez de Quiñones en el año $1673^{17}$. Fecha y autoría fueron mantenidas por Valencia de Redondo cuando la custodia se exhibió en el Pabellón de la Santa Sede de Sevilla con motivo de la celebración del V Centenario del Descubrimiento de América ${ }^{18}$. Sin embargo, en el año 2009 Fajardo Rueda admitió que, aunque la tradición la atribuye a los plateros payaneses, se desconoce su verdadero origen porque no existen documentos y porque la pieza sufrió importantes reformas en el siglo XVIII. En este contexto, considera, finalmente, que la custodia debió labrarse a fines del siglo XVII ${ }^{19}$.

Como puede apreciarse, las investigaciones se habían centrado en la localización, clasificación y descripción de las obras, y en la recogida de sus inscripciones y marcas. Un avance importante se produjo en el 1996 cuando se abordó por primera vez el análisis global del grupo, el origen y desarrollo de su iconografía, y su significado en un ámbito eucarístico, todo lo cual dio lugar a novedosas conclusiones. Según este estudio, el origen del águila bicéfala en un contexto sagrado y eucarístico se localizaría, desde el punto de vista formal y de contenido, en la estampa de María Antonia Beer que sirvió de portada a la obra del Sumo Sacramento de la Fe. Tesoro del Nombre Cristiano. A la S(acra) C(atolica), R(eal) Mag(estad del Rey N(uestro) S(eñor) D(on) Philipe IIII el Grande, Por el $P$ (adre) Francisco Aguado de la Comp (añi) a de Jesus. Predicador de su Mag(esta) d. Natural de M(adri)d. Con privilegio, publicado en Madrid por Francisco Martínez en el año 1640 (Figura 1) ${ }^{20}$.

La estampa reproduce el escudo imperial de los Austrias con el águila bicéfala coronada sujetando la esfera terrestre que soporta, a su vez, una custodia con el cáliz y la Forma rodeada de una gloria de rayos, nubes y querubines. El águila

una obra al mismo tiempo. En todo caso, la custodia de Valtierra la labró en Madrid en 1699 Cristóbal de Alfaro, sólo o en colaboración con un maestro de su entorno.

${ }^{15}$ Portilla Vitoria/Enciso/Azcárate Ristori, 1988: 699-700.

${ }^{16}$ La recogió Sebastián, 1990: fig. 49.

17 Fajardo Rueda, 1990: 55.

18 Valencia de Redondo, 1992: 325.

19 Fajardo Rueda, 2009: 36-40.

${ }^{20}$ Heredia Moreno, 1996: 189-192. 
apoya en un pedestal prismático entre las personificaciones de la Piedad y la Fortaleza, con una serie de inscripciones que aclaran el significado del conjunto y proclaman que Felipe IV, a quien va dedicada la obra, es el firme soporte terrenal del Sacramento de la Eucaristía, a cuya defensa y exaltación dedica todos los recursos a su alcance. En suma, en pleno auge de la Contrarreforma y en unos años difíciles para el monarca español, el blasón imperial se utilizaría fundamentalmente al servicio de una idea religiosa, pero también de propaganda política. La estampa y las ideas que conlleva la reinterpretaron después de 1640 los plateros de la corte madrileña en un grupo excepcional de custodias, labradas durante los últimos años del reinado de Felipe IV, Carlos II y comienzos del de Felipe V hasta la paz de Utrech. No obstante, el modelo se expandió fuera de estos límites geográficos y llegó a América, aunque de forma puntual, quizás a través de los jesuitas, orden a la que pertenecía el propio Francisco Aguado.

Además, en el referido trabajo de 1996 se supuso que la custodia de Alquézar (Huesca) era la que, fechada entre 1710-1715, se exhibió en la muestra de Orfebrería y Ropas de Culto junto a la del cabildo catedral de Madrid, si bien se indicaba que la pieza oscense podía ser anterior. Se apunta también que la donación de la custodia de las Agustinas de Salamanca pudo tener lugar en torno al 1656, año en que los VII condes de Monterrey contrajeron matrimonio y su sobrina Inés profesó en el convento. No obstante, se reconocía que el origen concreto y la fecha exacta de la donación eran difíciles de determinar puesto que el modelo no se ajustaba a los diseños madrileños ni salmantinos contemporáneos ${ }^{21}$. Años más tarde, se señaló su parecido formal con la desaparecida custodia de El Escorial reproducida en la pintura de Claudio Coello ${ }^{22}$. Finalmente, en el 2015 se documentó la de Monterrey como obra labrada por el platero y relojero real Francesco Filippini (+1695), artífice que había transformado el reloj de plata dorada que el emperador Leopoldo I regaló a su sobrino Carlos II, en una custodia para albergar la reliquia de la Santa Forma de El Escorial ${ }^{23}$.

En el año 2015 se añadió al grupo una suntuosa pieza, hoy desaparecida, que don Sebastián Hurtado de Corcuera, Gobernador, Capitán General y Presidente de las Islas Filipinas entre junio de 1634 y agosto de 1644, envió a la Capilla Real del Alcázar de Madrid junto con otras alhajas para la reina Isabel de Borbón ${ }^{24}$. El documento recoge "- Primeramente un viril de una custodia con diamantes, rubíes y esmeraldas tasado en la almoneda en doscientos setenta pesos de plata

${ }^{21}$ Heredia Moreno, 1996: 192.

${ }^{22}$ Cruz Valdovinos, 1999: 592.

${ }^{23}$ Cruz Yábar, 2015: 96-97. Los datos proceden del testamento de Filippini, publicado por Saltillo, 1955: 13-14, que hasta entonces no se habían tenido en cuenta.

${ }^{24}$ Martín, 2016: 243-251. 
y costó treinta y tres $\mathrm{mil}^{25}$. - El pie de dicho viril de filigrana de oro que no tenía puestas las piedras si no solo los encages. -Un águila imperial tan grande como una tórtola, con dos cabezas abiertas, con las alas de filigrana de oro cuajadas de piedras rubíes y esmeraldas y coronadas las cabezas con diamantes, para poner a los pies de la custodia y -Dos leoncillos para los lados de dicha águila”. Se incluyen también en esta relación una urna de oro con su tapadera y cruz de dos brazos, un cáliz de oro con su patena y cruz de Alcántara esmaltada, unas palabras de la consagración, un portapaz de filigrana de oro con la imagen de Nuestra Señora y su Hijo, un tabernáculo de filigrana de plata, y tres docenas de candeleros para ponerlos dentro del tabernáculo. Los regalos para la Reina comprendían un escritorio con su bufete de estrado, otro escritorio y seis baulitos, todos ellos de filigrana de plata.

A partir de éstos y de otros datos documentales, el estudio analiza la trayectoria del donante, la traza y ornamentación de la pieza, y las vicisitudes de la misma a lo largo de su azaroso viaje desde Manila hasta la Corte de Madrid. Se indica que cuando el gobernador fue depuesto de sus cargos, su sucesor don Diego Fajardo mandó vender las alhajas, pero que la custodia no tuvo salida en la almoneda y se depositó en la Caja Real de Manila el 24 de julio de 1645. Los Jueces y Oficiales de la Real Hacienda la describieron y tasaron en los siguientes términos: “. ..una custodia de oro, esmaltada de diamantes, con sus rayos y su pie [...] tiene las piezas siguientes. Veinte rayos y en cada uno 12 diamantes rosas pequeños y el del extremo mayor, y el rizo con 52 diamantes delgados; y el cerco de dicha custodia, que llaman cañón con dos diamantes rosas grandes en lo alto y diez diamantes fondos grandes, ocho rubíes brutos y cuatro esmeraldas grandes, las dos cuadradas y las otras dos prolongadas; cuatro flores de lises, con veinte siete esmeraldas cada una y en el extremo un diamante rosa, que todo como esta pesó con una vidriera cincuenta y dos quilates, por la tasación que hicieron el Almirante Luis Alonso de Roa, Manuel Guerrero, fiel contraste de esta ciudad y Antonio de Aguilar, platero de oro, que fueron nombrados por auto del dicho Señor Gobernador, a pedimento del Señor Fiscal. Los cuales tasaron unánimes y conformes la dicha custodia en veinte y seis mil pesos de oro..." ${ }^{26}$.

Años después, en 1653, el propio Hurtado de Corcuera envió al Rey un memorial donde adjuntaba la relación de las alhajas que había mandado realizar para la Capilla Real y para la Reina, y valoró la custodia en 33.000 pesos. En el

${ }^{25}$ La cifra debe ser un error de transcripción, ya que el valor del viril en el documento original del Archivo General de Indias (AGI), Filipinas, 4, N. 41, es de 26.000 pesos.

${ }^{26}$ AGI, Filipinas, 2, N. 175. Recogido por Martín, 2016: 247. 
1670 se remitió a Veracruz y se procedió a su traslado a España en la capitana de la flota de $1671^{27}$, llegando a la Corte madrileña en agosto de este mismo año ${ }^{28}$.

Recientemente, Sigaut ha puesto en duda varias cuestiones sobre alguna de estas obras y sobre su origen iconográfico, indicando que "A partir de un desmontaje analítico pretende revertir un presupuesto historiográfico según el cual, los modelos - de cualquier cosa- tenían que salir de la corte"29. Su crítica y sus razonamientos se concentran en la custodia de Manila y en la del convento de Agustinas de Salamanca. Por lo que respecta a la custodia filipina, describe de nuevo la trayectoria profesional del gobernador don Sebastián Hurtado de Corcuera y sus donaciones de plata. Considera que Hurtado de Corcuera cambió el valor de las alhajas a lo largo del tiempo -en 1648 y en 1653-, así como su destino - para el colegio de San Felipe de Manila, para la reina y para la capilla real de El Escorial-y lo califica de mentiroso y liante para lograr el favor del rey ${ }^{30}$. También afirma que el 25 de julio de 1672 la reina Mariana de Austria mandó al Duque del Infantado, Mayordomo Mayor del Rey, que el Guardajoyas pusiera "a disposición del Conde de Medellín la custodia de Hurtado de Corcuera que el Consejo de Indias dispuso se hiciese para la Real Capilla, para tasar su valor y hechura". Es decir, piensa que la custodia era un regalo del Consejo de Indias. Además, da por supuesto que la obra se había labrada antes de 1638, posiblemente entre 1627-1633, en Perú o en Panamá donde Corcuera residió durante estos años, y que, por tanto, este modelo, llegado de las Indias, fue la cabeza de serie que inspiró a los plateros madrileños de la Corte. También ordenó la Reina que el águila bicéfala se incorporase en una lámpara que regaló a El Escorial en el año 1690.

En cuanto a la custodia de las agustinas de Salamanca, Sigaut vuelve a mencionar su relación con la de la pintura de Claudio Coello de la sacristía de El Escorial alusiva al conocido episodio de 1677 contra el valido Valenzuela por parte de la nobleza madrileña y a la primera traslación de la Sagrada Forma de Gorkun en el año 1684 tras la liberación de Viena. Considera que ambas piezas pueden tener en común su origen como relicarios y asegura que la de El Escorial es el reloj que el emperador Rodolfo II había regalado a su sobrino Carlos II. Afirma también que el reloj se tasó en 240 reales, que llegó al monasterio en 15 de mayo de 1678 y que fue robado en el año 1942, aunque se conoce a través de una antigua

${ }^{27}$ Estos datos junto con la descripción de la custodia los publicó Heredia Moreno, 2012: 69 y 78 .

${ }_{28}$ AGI, Filipinas, 330, L.6, F.244V-245R. Real Cédula al presidente y oidores de la Audiencia de Manila, para que envíen a España con toda seguridad y brevedad la custodia de diamantes que se embargó a Sebastián Hurtado de Corcuera y que se halló en poder del gobernador Diego de Salcedo. Al margen: 'Esta custodia llegó a esta corte y vino en la flota de agosto del año de 1671".

${ }^{29}$ Sigaut, 2017: 70-92. El subrayado es nuestro.

${ }^{30}$ Sigaut, 2017: 75. 
fotografía. Además, atribuye los retratos de la base de ambas piezas al pintor flamenco Jan van Kessel II a finales de la década de 1670. Estas relaciones se explicarían por los contactos mantenidos entre los condes de Monterrey y el Monarca a través de su hermano don Juan José de Austria.

Finalmente, la autora concluye su estudio afirmando que: "Un presupuesto historiográfico de dependencia, impidió que los investigadores dedicados al análisis de la platería, pudieran suponer siquiera que el modelo del águila bicéfala fuera una fórmula originada en un lugar exógeno a la corte para aludir a la monarquía, y que un objeto precioso llegado de las Indias se hubiera convertido en un modelo para los plateros al servicio del rey. Con este trabajo pretendo revertir este presupuesto y poner el modelo perdido de la custodia de Hurtado de Corcuera, como el modelo copiado y seguido por los plateros de la corte, aunque las que éstos hicieron, no tuvieron el caudal de piedras preciosas y esmaltes que hacen únicas a las custodias americanas".

La velada crítica que se desprende de estas conclusiones, sobre la parcialidad y sobre la falta de rigor y de criterio científico de los historiadores españoles dedicados al estudio del arte de la platería, así como la confusión generada por las inexactitudes y errores que se intercalan a lo largo del texto, hacen necesario una profunda revisión del tema para tratar de esclarecer algunos puntos oscuros. Aprovecharemos también para precisar ciertos datos y para incorporar al grupo una nueva pieza.

Iniciando nuestro análisis por la custodia filipina, el memorial que don Sebastián Hurtado de Corcuera envió a Felipe IV en el año 1653 es bastaste esclarecedor y echa por tierra muchos de los calificativos que la citada autora dedica a nuestro personaje. El memorial comienza afirmando que:

"Hallandome sirviendo a V.M. en las Philipinas dispuse se labrase para la Capilla $\mathrm{R}(\mathrm{ea}) 1$ una custodia de diamantes rubíes y esmeraldas por haver entendido que V.M. havia hecho colocar el S(anti)S(i)mo. Sacram(en)to en ella por su gran devoción con otras cosas onrrosas cuya memoria di en Mexico al conde de Alba de Aliste $[\ldots]^{\prime \prime 31}$.

Este comentario responde a un hecho cierto y se refiere en concreto a las fiestas que se celebraron en Madrid el primer jueves de Cuaresma del año 1639 cuando se instaló el Santísimo en la Capilla Real del Alcázar madrileño, en virtud de una bula otorgada por Gregorio XIV en el $1591^{32}$. El cronista de Felipe IV, León Pinelo, y otros contemporáneos las describen y las califican como uno de los acontecimientos religiosos más memorables del reinado ${ }^{33}$. Participaron en este evento don Alonso Pérez de Guzmán el Bueno, capellán mayor del Monarca,

\footnotetext{
${ }^{31}$ El documento original en AGI, Filipinas, 4, N. 41.

${ }^{32}$ Heredia Moreno, 2016: 237-238.

33 Pinelo, 1931: 316.
} 
y el jesuita Francisco Aguado, confesor del Conde Duque de Olivares y autor del Sumo Sacramento de la Fe que se publicaría pocos meses más tarde ${ }^{34}$.

Por lo tanto, Hurtado de Corcuera no mentía ni trataba de liar a nadie sobre este asunto. Además, si la custodia se labró durante los años de su gobierno en Filipinas y tras conocer la introducción del Santísimo en la Capilla Real del Alcázar madrileño, es evidente que el encargo se produjo después de 1639. Es posible que la noticia llegara a Manila a través de algún jesuita, ya que don Sebastián estaba muy relacionado con la Orden de San Ignacio a la que había puesto al frente del gobierno del Colegio de San Felipe. Tampoco descartamos que el presunto viajero llevase consigo un volumen del Sumo Sacramento de la Fe. En todo caso, teniendo en cuenta las enormes distancias y las muchas etapas y dificultades del viaje entre Madrid y Manila -por tierra desde Madrid hasta el puerto de Sevilla, larga travesía por mar en la flota de Nueva España hasta Veracruz, nuevo desplazamiento por tierra atravesando México hasta el puerto de Acapulco en el Pacífico y otra larga travesía marítima en el galeón de Manila-, suponemos que Hernando de Corcuera no tuvo conocimiento de estos sucesos hasta un par de años después ${ }^{35}$. Es decir, la custodia se labraría en Manila entre 1642 y $1644^{36}$.

El memorial también deja claro y distingue el destino de todas y cada una de las alhajas, tanto las que iban dirigidas a la Capilla Real de Su Majestad, como los regalos destinados para la Reina ${ }^{37}$. Hernando de Corcuera indica que todas "las cossas encaxonadas, bien acomodadas, retuladas para quien eran se allaron en mis alaxas y todas se vendieron por mucho menos de su justo valor y lo que costaron". A este respecto recordamos "Un viril de una custodia que fue tasada en la almoneda en 27.000 pesos de plata" ${ }^{38}$. Sin duda se trata de un precio inferior a los 33.000 pesos que, según su propia declaración de 1653, había pagado por ella, pero la diferencia puede deberse a las circunstancias concretas de cada tasación y a que los tasadores fueron distintos en cada caso. Por lo tanto, no se trata de ningún cambio de opinión de don Sebastián, como se afirma en el texto de 2017. Es más, la custodia se depositó en la Real Caja de Manila en 24 de julio de 1645 donde, como hemos visto, fue tasada de nuevo por el contraste de la

\footnotetext{
${ }^{34}$ Heredia Moreno, 2016: 237-238.

35 Sobre las dificultades y la duración de estos viajes, Serrera, 1989: 333-342. Serrano Mangas, 1989: 323-332.

${ }^{36}$ Origen y fecha coinciden con la opinión de Martín, 2015: 249, que también afirma que la custodia fue encargada en Manila durante los primeros años de la década de los cuarenta del siglo XVII.

${ }_{37}$ Martín, 2015: 243-245, transcribe la relación completa del documento original.

${ }^{38}$ AGI, Filipinas, 2, N. 172, Orden de 29 de julio de 1657. Consulta sobre residencia de Hernando de Corcuera. Memoria de las cosas que tenía hechas para la Capilla y se las quitó y vendió D. Diego Faxardo. Los 270 pesos que recoge Fernando Martín en lugar de 27.000 son claramente una errata.
} 
ciudad Manuel Guerrero y por el platero de oro Antonio de Aguilar que estimaron su valor en 26.000 pesos de oro.

El 4 de noviembre de 1648 ingresaron en la misma Real Caja las otras alhajas que se habían salvado de la almoneda, a saber, una caja de plata de filigrana con su llave que contenía dos leoncillos, cuatro pilaretes, siete varillas, un hábito de Alcántara y una cruz pequeña. Sin embargo, a pesar de varias solicitudes de los gobernadores y de un par de cédulas reales que las reclamaban, todas ellas permanecieron en la Caja Real de Manila hasta 1670 y no se enviaron a España hasta el año siguiente. Una carta del marqués de Mancera, virrey de Nueva España, fechada en 27 de marzo de 1671 notifica que "La custodia de oro, una caja de plata y una águila de oro" se remitían a la Casa de la Contratación de Sevilla en la nao capitana de la flota de dicho año ${ }^{39}$.

También hay que descartar la afirmación de Sigut de que, tras la llegada a Madrid, Mariana de Austria mandó tasar la custodia de Hurtado de Corcuera que el Consejo de Indias dispuso se hiciese para la Real Capilla ${ }^{40}$. Los datos relativos a la tasación de una custodia son ciertos, pero no se refieren a la pieza procedente de Filipinas sino a otro ejemplar de oro, diamantes, rubíes y esmeraldas que, por estas mismas fechas, los artífices madrileños Luis de Zabalza y Simón Navarro, plateros de cámara y de la reina Mariana de Austria, acababan de labrar para la Capilla Real del Alcázar de Madrid, por orden del VII Conde de Medellín, Presidente del Consejo de Indias. Esta última obra sí que fue tasada por el platero de cámara Juan Bautista de Villarroel y por Francisco de Payba, asimismo platero, que estimaron su valor en 12.000 ducados $^{41}$.

De la custodia filipina no volvemos a tener noticias. En el terreno de la hipótesis cabe pensar, como se indicó hace varios años, que quizás llegase a la Corte muy deteriorada, tras haber sufrido tantos avatares y un largo y azaroso viaje, y que sus materiales se reaprovecharon en otra pieza de nueva hechura o que sus piedras preciosas se integraron en el ejemplar madrileño recién labrado por Zabalza y Navarro. De hecho, en el inventario post mortem de Carlos II fechado en 1701 se cita en el número 2 del Relicario "La custodia rica. Una custodia de Oro, diamantes, Rubíes y esmeraldas que es la que sirve en los descubiertos de la $\mathrm{Ca}$ pilla Real [...] que en ttodo son los diamantes y piedras de dicha Custodia seis mil trezienttos y veinte y nueue diamantes=Dos mil y quarentta y tres Rubíes y ochoçienttos y cinquentta y un esmeraldas no se tasó por ser para el culto divino". Es decir, el texto se refiere a una tercera pieza confeccionada con los mismos materiales, pero con un número mucho mayor de piedras preciosas que la de

\footnotetext{
${ }^{39}$ AGI. México, 45, N. 11.

${ }^{40}$ Sigaut, 2017: 77.

${ }^{41}$ Heredia Moreno, 2016: 243. El documento original en AGI. Indiferente, 440, L. 26, f.441v.
} 
Hurtado de Corcuera y que la de Zabalza y Navarro ${ }^{42}$. Según el documento recogido en páginas anteriores, la custodia de Manila tenía en total 328 diamantes, 8 rubíes y 31 esmeraldas de distinto tamaño y valor ${ }^{43}$. Sobre la custodia de Zabalza y Navarro no tenemos datos tan precisos, pero su precio tampoco permite identificarla con el riquísimo ejemplar del relicario del Alcázar de Madrid.

Además, los términos de la mencionada carta del marqués de Mancera notificando el envío de "La custodia de oro, una caja de plata y una águila de oro", permiten aventurar que tanto el marqués como los Reyes consideraron que se trataba de tres piezas distintas e independientes.

Hay noticias de que, el 18 de octubre de 1690, doña Mariana de Austria remitió al Padre Prior de San Lorenzo de El Escorial "una alhaja" para la Capilla que se hizo en la Sacristía, que se viene identificando con la "araña de seis luces de la misma materia de la custodia grande" citada en otro documento sin fecha ${ }^{44}$. También la menciona el barón Godolphin, embajador inglés en la corte madrileña, como "una araña de oro, plata, filigrana y pedrería" ${ }^{45}$. El Padre Ximénez afirmaba en 1764 que "Tienenla asida en lo alto dos águilas con corona de oro"46. Por último, Cruz Yábar indica que "se componía de un gran globo central del que salían seis arandelas con adornos y colgantes de frutas, que descendían hasta una manzana en que remataba, y todo el conjunto estaba sostenido por dos águilas imperiales con las cabezas unidas bajo una sola corona de oro" ${ }^{47}$. De estas descripciones se desprende que la lámpara estaba sujeta por un águila bicéfala. Pero se trataría de una pieza de gran consistencia, capaz de soportar todo el peso y, por tanto, distinta de la figura filipina hecha de filigrana de oro.

Es más factible que el águila de Manila se incorporase en el portapaz que el mismo don Sebastián había mandado a la Corte años atrás, a saber "Un portapaz de filigrana de oro con la imagen de Nuestra Señora y su Hijo, de pincel, este está ya en la Capilla Real, que lo traia un religioso agustino para llevarle a Roma y con la noticia que hubo mia el Patriarca, se trajo a la Capilla"48. A este respecto, el número 83 del inventario "post mortem" de Carlos II recoge en el año 1701 "Vn portapaz de oro de echura de filigrana con un pedrestal quatro colunas cornisa y medio punto: Vna cruz y quatro pirámides por remate y en medio del Vn águila Ymperial guarnezida de Granates con Vna luminazión de nuestra señora en medio de ella y por la parte de atrás Vna asa toda de oro de feligrana" ${ }^{49}$.

\footnotetext{
${ }^{42}$ Fernández Bayton, 1975: 366-367.

43 AGI, Filipinas, 2, N. 175.

${ }^{44}$ Mediavilla O.S.A., 2003: 209.

45 El testimonio lo recoge Maura Gamazo, 2018: 399. 1.

46 Ximénez, 1764: 298.

${ }^{47}$ Cruz Yabar, 2015: 116.

48 AGI, Filipinas, N.41. Recogido por Martín, 2015: 245.

49 Fernández Bayton, 1975: 381. Recogido en Heredia Moreno, 2016: 248.
} 
Por otra parte, Doña Mariana de Austria ordenó en 1674 que "la caja de filigrana de plata, en que vino de Indias la custodia rica de la Real Capilla [y] se entregue a Don Diego Bonifaz Gobernador de Aranjuez para que esta Semana Santa sirva de Arca de depósito del SSmo. Sacramento de la Capilla del Palacio de aquel Real Sitio y que acabada la función se vuelva al guardajoyas del Rey Ntro. Sr. donde está al presente" ${ }^{50}$. Esta orden es otro dato a favor de que, tras su llegada al Alcázar madrileño, la custodia, la caja y el águila de Manila se utilizaran por separado en distintos momentos y lugares, porque se consideraron tres piezas diferentes. Por lo tanto, no parece verídico que el ostensorio filipino fuese el punto de partida de los plateros de la Corte, aunque alguno de ellos pudo tener ocasión de verlo "Con el águila colocada a sus pies". Tampoco es creíble que sirviese de inspiración para los artífices hispanoamericanos. No olvidemos que Hurtado de Corcuera lo mandó labrar en Filipinas entre 1642 y 1644, y que permaneció en la Caja Real de Manila desde 1645 hasta 1670. Este mismo año se transportó a México y, desde allí, de manera inmediata, se mando al puerto de San Juan de Ulúa en Veracruz para su traslado a España. Además, ni en Filipinas ni en toda la América hispana conocemos ninguna otra custodia semejante. La excepción sería la de Popayán que se labró más tarde y que tampoco se pudo inspirar en la de Manila, ya que ésta nunca estuvo en Colombia y los plateros payaneses no tuvieron ocasión de verla en ningún momento. Es decir, según el estado actual de la cuestión, el punto de partida de la pieza colombiana tuvo que ser también, directa o indirectamente, la estampa, o su descripción, del Sumo Sacramento de la Fe, que sí pudo llegar a Colombia a través de la propia Orden Jesuita. En todo caso, su repercusión en los países hispanoamericanos fue nula. Al menos no se ha localizado hasta el momento ninguna otra custodia con este tema iconográfico.

La figura del águila bicéfala sí se incorporó en otras tipologías del ajuar litúrgico y gozó de fortuna en México a lo largo del siglo XVIII. Así lo demuestran las obras de esta procedencia que se conservan en ambos lados del Atlántico, como los atriles sacras del Pilar de Zaragoza (1715), los del Museo Franz Mayer de México (1700-25), o el marco de la catedral de Burgos (1750-75), entre otros ejemplos ${ }^{51}$.

Por lo que concierne a la custodia del convento de agustinas de Salamanca, hace varios años se documentó que su artífice fue el platero y relojero Francesco Filippini ${ }^{52}$, lo que aclara las anteriores interrogantes sobre su origen y explica sus diferencias formales respecto a las demás piezas del grupo, salvo por la presencia del águila bicéfala en el astil (Figura 2). Su relación formal con el viril donde

${ }^{50}$ Archivo General de Palacio (AGP), Administración, legajo 906: Guardajoyas 1670 a 1679, 1674. Recogido por Sigaut, 2017: 77.

${ }^{51}$ Recogidos en Heredia Moreno, 1996: 193-194.

${ }^{52}$ Cruz Yábar, 2015: 96-97. 
se alojó la Sagrada Forma de Gorkum de El Escorial se explica también porque fue el propio Filippini el que estuvo implicado en su transformación y aderezo para adecuarlo a su nuevo uso.

Dejamos al margen, en la medida de lo posible, la historia de la Sagrada Forma y los sucesos que motivaron la renovación y enriquecimiento de la sacristía de El Escorial con su complejo programa iconográfico, para centrarnos de forma exclusiva en la propia custodia ${ }^{53}$. Como es bien sabido, esta pieza era un suntuoso reloj de plata dorada, filigrana y piedras preciosas, valorado en 24.000 pesos, que Carlos II había recibido como obsequio de su tío el emperador de Alemania Leopoldo I ${ }^{54}$. El monarca español lo ofreció al monasterio de El Escorial como medida expiatoria para que su corte obtuviese la absolución por la sacrílega invasión de su espacio sagrado por parte de la nobleza española para derrocar a don Fernando Valenzuela, valido de doña Mariana de Austria ${ }^{55}$.

El 28 de julio de 1678 fray Diego de Ciudad Real, monje profeso del Real Monasterio de San Lorenzo de El Escorial, notario público apostólico, da fe de que el reloj ya se encontraba en su biblioteca y lo describe de forma minuciosa ${ }^{56}$. También es muy detallada la descripción del Padre fray Francisco de los Santos en la cuarta parte de la Historia de la Orden de San Gerónimo ${ }^{57}$.

De éstos y de otros testimonios se desprende que el reloj era una gran caja o estructura de plata sobredorada guarnecida de filigrana de plata en su color, cuajada de piedras preciosas, con tres cuerpos y una altura total que superaba los 3 metros. Su adorno incluía numerosos colgantes y flores, así como algunas figuras mitológicas y simbólicas. En el segundo cuerpo se albergaba el reloj propiamente dicho que, con las pertinentes modificaciones, se transformó en una custodia portátil. Una suntuosa pieza de oro, plata y filigrana recubierta de piedras preciosas,

${ }^{53}$ Sobre este tema puede consultarse la nota anterior. También Fernández-Santos Ortiz-Iríbar 2001: 663. Otros títulos se recogen en las notas siguientes.

${ }_{54}$ Alberto I (1640 -1705) fue Rey de Hungría desde 1655, de Bohemia desde el año siguiente y Emperador del Sacro Imperio Romano Germánico a partir de 1658. Mediavi1la O.S.A., 2003: 209, lo confunde con Rodolfo II, aunque en los documentos que aporta transcribe el nombre correcto. En cambio, Sigaut, 2017: 84, mantiene el error sin tener en cuenta que Rodolfo II (1552-1612) murió casi cuarenta años antes del nacimiento de Carlos II.

${ }_{55}$ Maura Gamazo, 2018: 399-400. El regalo se lo entregó el embajador conde de Trautson. Al parecer traía también para doña Mariana de Austria una pila de agua bendita con la imagen de Nuestra Señora y las armas imperiales, cubierta de diamantes, y una araña de oro, plata, filigrana y pedrería. Esta última pieza es la que la Reina regaló a la sacristía de El Escorial varios años después.

${ }^{56}$ Mediavilla O.S.A., 2003: 205-234.

${ }^{57}$ Recogido por Maura Gamazo, 2018: 399, nota 2. 
de vara y cuarta de alto, idónea para cobijar la Sagrada Forma ${ }^{58}$. Esta custodia fue robada en 1942, pero se conoce a través de la pintura preparatoria para el lienzo de Claudio Coello (Figura 3) y de una antigua fotografía que revelan su inusual nudo esferoide compuesto por puntas que simulan rayos ${ }^{59}$. Según otro documento, fechado el 1 de agosto de 1682, el encargado de realizar estos cambios para adaptarla a su nuevo uso había sido el relojero y platero don Francisco Filippini que la entregó al monasterio en $1678^{60}$. La custodia mereció los elogios del Padre Ximénez que tuvo ocasión de verla en el siglo XVIII: "dentro de esta custodia grande hay otra pequeña, de la altura de un cáliz, muy exquisita, donde esta colocada la Santa Forma: remata en una estrella, como venida del Cielo para ministerio tan alto..."

A partir de todas estas noticias cabe deducir que Filippini recreó el sol y la peana de la custodia escurialense en la que le encargaron los VII condes de Monterrey para el convento de agustinas de Salamanca, incluyendo incluso los medallones pintados con sus retratos y con la imagen de la Inmaculada, a semejanza de los retratos de los Reyes y el de don Juan José de Austria que tenía la de El Escorial. Pero Filippini sustituyó el nudo espinoso de la custodia de la Santa Forma por un águila bicéfala, de acuerdo con uno de los modelos difundidos en la Corte en estos momentos. Dado que el platero falleció en el año 1695 y que, a su muerte, los condes todavía le debían 1500 ducados, es probable que la custodia de Salamanca se labrase en fechas próximas, aunque tampoco puede descartarse por completo una cronología anterior. Recordemos que Francesco Filippini, "hombre de agudo ingenio", natural de Sant'Agata Feltria, estado de Urbino, había vivido en Roma pero se trasladó a Madrid antes de 1674, fecha en que contrató el reloj de la Casa de la Panadería de la Plaza Mayor. A partir de entonces desplegó una importante y variada actividad como platero, relojero, broncista y cerrajero, tanto para los Reyes en la sacristía del Escorial, como para don Juan José de Austria en la capilla del Milagro de las Descalzas Reales de Madrid ${ }^{62}$.

$\mathrm{Su}$ adaptación del reloj para custodia de la Santa Forma tuvo lugar en 1677, tras la excomunión de los implicados en el citado asunto del valido Valenzuela. Entre ellos se encontraba el VII conde de Monterrey, partidario de don Juan José de Austria y en contra de Valenzuela. Estas críticas circunstancias parecen un momento idóneo para que el conde, a imitación del monarca, regalase al convento salmantino del que era patrono una custodia semejante a la de El Escorial pero inspirada formalmente también en la estampa del Sumo

${ }^{58}$ Mediavilla O.S.A., 2003: 224-225. El memorial incluye las piezas donadas por Carlos II al Monasterio.

59 Stepánek, 1990: 30-36.

${ }^{60}$ Mediavilla O.S.A., 2003: 218-219, doc. 9.

${ }^{61}$ Ximénez, 1764: 296.

62 Yábar, 2015: 104. 
Sacramento de la $\mathrm{Fe}^{63}$. De esta forma proclamaba su fervor al Sacramento de la Eucaristía, igual que el propio monarca, y recreaba una iconografía similar a la de los Austrias para mayor gloria de su propio linaje. El resultado fue una pieza excepcional en la que Francesco Filippini supo conjugar el primitivo modelo alemán con la iconografía eucarística surgida en Madrid en tiempos de Felipe IV, donde se integraban también los retratos de los donantes y sus devociones preferentes, en este caso el culto a la Inmaculada Concepción y el culto a la Eucaristía. Es posible, como indicó Sigaut, que estos retratos sean obra del conocido maestro flamenco Jean Van Kessel II, retratista y miniaturista, establecido en la corte madrileña hacia 1679 , que llegó a ser pintor de Carlos II y de Mariana de Neoburgo ${ }^{64}$. Todas estas circunstancias explican la originalidad y las diferencias, pero también las semejanzas, de la custodia salmantina con los ejemplares de águila bicéfala que estaban labrando lo plateros madrileños por estas fechas, un modelo que se repitió con variantes durante casi medio siglo, entre finales de los años setenta del XVII y las primeras décadas del XVIII. En todo caso, descartamos la fecha de 1656 que se propuso para la ejecución de esta obra y pensamos que tuvo que labrarse después de 1678.

A juzgar por los datos conocidos hasta ahora, las primeras custodias de este grupo se labraron a comienzos del último cuarto del siglo XVII. La de la parroquia de San Martín de Cartes (Cantabria), la más sobria de todas, con la decoración reducida al águila y a las estrellas del sol, lleva la fecha de 1680. $\mathrm{Su}$ basamento cuadrangular con ensanches rectangulares en sus frentes se asemeja al de la custodia de Orduña que dio de limosna el capitán don Antonio de Odiaga Lezama ${ }^{65}$, pero la vizcaína, obra del platero real Rafael González Sobera en $1683^{66}$, resulta mucho más rica y espectacular por la abundante pedrería polícroma superpuesta por toda la pieza (Figura 4$)^{67}$.

De cronología semejante, quizás de finales de los años setenta, parece la custodia de la iglesia del castillo de Alquézar (Huesca) con basamento circular, rayos lisos -rectos y flameados- y ornamentación reducida a los florones vegetales repujados en la base (Figura 5). Es muy probable, como indicó Esquíroz, que fuera

${ }^{63}$ Descartamos la fecha de 1657 propuesta en 1996 a favor de una nueva cronología entre 1678 y 1694.

${ }^{64}$ Sobre este asunto Sigaut, 2017: 88, se basa en el artículo de Simal López, 2017: 29-52.

${ }^{65}$ Heredia Moreno, 2018: 256-261.

${ }^{66}$ Rafael González Sobera fue platero real desde el año 1655 y en el 1658 labró la urna de plata para el cuerpo incorrupto de San Diego en su capilla del convento franciscano de Santa María de Jesús de Alcalá de Henares que hoy se conserva en la catedral complutense. Vid. Heredia Moreno, 1999: 154-156.

${ }^{67}$ Desconocemos la razón por la que esta pieza labrada en Madrid por un platero de la corte se incluye entre las custodias iberoamericanas que recoge Martín Vaquero, 2020: 349-350. 
donación de algún miembro de la familia Nasarre, infanzones aragoneses de origen medieval que establecieron su casa solariega en esta localidad oscense. Tras la conquista de Huesca se les confió la guarda del castillo y en 12 de noviembre de 1585 Felipe de Nasarre obtuvo el título de alcaide de la villa ${ }^{68}$. No obstante, hay que descartar su identificación con la que se exhibió en la Exposición de Orfebrería y Ropas de Culto, que hoy pensamos debía ser el "hermosísimo ejemplar de gran riqueza y complicada hechura, único en la provincia" que se guarda en la iglesia de San Eutropio de El Espinar (Segovia) y que hasta ahora no se había tenido en cuenta ${ }^{69}$. Su parecido con la desaparecida del cabildo catedral de Madrid “de sol lobulado sobre pie con águila fechada en 1712" permite identificarla con la que se mencionó como "muy semejante a la anterior" y se fechó hacia 1715 (Figura 6) ${ }^{70}$. Casi idéntica es también la del convento de carmelitas de Alba de Tormes, obra madrileña del último tercio del XVII ${ }^{71}$.

Muy semejante a las tres anteriores es también la custodia de la parroquia de Valtierra, labrada en Madrid en 1699 por, o en el entorno de, Cristóbal de Alfaro, miembro de una dinastía de plateros navarros establecidos en la Corte (Figura 7) ${ }^{72}$. Lleva la señal del marcador de villa Juan Muñoz -JU/MUÑOZ- utilizado entre 1695 y 1712 . Los cuatro ejemplares, de plata sobredorada con el viril de oro y enriquecidos con esmaltes o piedras preciosas presentan un magnífico y elaborado diseño. Se elevan sobre amplia base mixtilínea con pestaña moldurada y plataforma convexa plana. Astil con gran águila bicéfala con las alas explayadas en cuyas coronas apoyan figurillas sedentes con cuernos de la abundancia (Valtierra) o niños tenantes (Alba de Tormes). El sol, idéntico en las cuatro piezas, se compone de un cerco polilobulado con pedrería sobrepuesta, resplandor de gruesos rayos que forman una crestería calada con remates de estrella y un viril circular interior que repite simplificado y a escala menor el diseño anterior. La estructura se enriquece por numerosas tornapuntas en el astil y por los desnudos infantiles sobre la base, todo lo cual contribuye al barroquismo y a la suntuosidad del conjunto. Por todo ello, parece indudable que se trata de obras madrileñas labradas por Cristóbal de Alfaro o por su círculo próximo entre 1695 y $1715^{73}$.

Por último, el expositor del Museo Diocesano de Salamanca procedente de La Real Clerecía de San Marcos, obra de Luis García Crespo a mediados del XVIII (Figura 8), incluye el viril en el cuerpo del águila, a medio camino entre el grupo de custodias que estamos tratando y las sacras aquiliformes que proliferaron por

\footnotetext{
68 Mur Ventura, 1929.

69 Arnáez, 1985: 264, fig. 289.

70 Camps Cazorla, 1941: 83, sala VII, nºs. 1 y 2.

71 Pérez Hernández, 1990: 189. De 79'7 cm de alto, de plata dorada y esmaltes.

72 Remitimos a los comentarios que efectuamos en páginas anteriores en la nota nú-

73 Heredia Moreno, 1996: 191-192.
} mero 15 . 
España e Hispanoamérica desde comienzos del siglo, como antes comentamos, y que el propio García Crespo difundió por Salamanca y zonas limítrofes, como la de la iglesia de La Seca (Valladolid) y la de la catedral salmantina o la que labró Manuel Pérez Espinosa en el último cuarto del setecientos para la iglesia de San Vicente de Zamora ${ }^{74}$.

A tenor de lo expuesto, con las salvedades y precisiones que hemos ido detallando a lo largo del texto, reafirmamos la tesis defendida en 1996 e insistimos en que el punto de partida de la iconografía del águila bicéfala en las custodias portátiles se localiza en la citada estampa de María Antonia Beer del año 1640. No obstante, el grabado no se materializó en una obra de plata durante el reinado de Felipe IV. La custodia de Corcuera fue una excepción que pudo labrarse a partir de una descripción verbal. De ahí que el águila no estuviese integrada en la estructura, sino que fuese una pieza exenta "para ponerla a sus pies" junto con un par de figuras de leones. En todo caso, el modelo no cristalizó hasta finales de los años setenta, cuando las circunstancias políticas y religiosas de la corte de Carlos II hicieron preciso recuperar y materializar el tradicional fervor eucarístico de los Austrias españoles con el fin de neutralizar al máximo las nefastas consecuencias del episodio de Valenzuela en los círculos cortesanos. El modelo se prolongó tras la llegada al trono de Felipe $\mathrm{V}$, quizás como forma de enlace y de continuidad entre la dinastía de los Austrias y la de los Borbones, en unos años en que el espíritu de la Contrarreforma con su interés por el culto a la Eucaristía y a las reliquias estaba todavía en pleno vigor. De ahí que fueran los plateros de la corte madrileña, cercanos a los monarcas y en el entorno de la nobleza, los que se encargaron de plasmar estas ideas.

Fecha de recepción: 22 de septiembre de 2020.

Fecha de aceptación: 2 de mayo de 2021.

\section{BIBLIOGRAFÍA.}

Aranda Huete, Amelia (1999): La joyería en la corte durante el reinado de Felipe $V$ e Isabel de Farnesio. Madrid: Fundación Universitaria Española.

Arco y Garay, Ricardo del (1921): Catálogo Monumental de Huesca. Madrid: manuscrito consultado en los fondos digitalizados de la biblioteca cchs.csic.es, vol. I.

Arnáez, Esmeralda (1985): Orfebrería religiosa en la provincia de Segovia en los siglos XVIII y XIX. Madrid.

Camps Cazorla, Emilio (1941): "Sección de orfebrería". En: Catálogo de la Exposición de Orfebrería y Ropas de Culto. Madrid: Museo Arqueológico Nacional.

${ }^{74}$ Pérez Hernández, 1990: 248 y 294. Samaniego Hidalgo, 1987:130. 
Carretero Rebes, Salvador (1986): Platería religiosa del Barroco en Cantabria. Santander: Institución Cultural de Cantabria y Ediciones de Librería Estudio.

Cruz Valdovinos, José Manuel (1999): "Platería”. En: Bartolomé Arraiza, A1berto (coord.): Las artes decorativas en España. T. II. Madrid: Espasa Calpe, pp. 513-610.

(2015): "El retablo de la Sagrada Forma de El Escorial. Circunstancias de su patrocinio, programa iconográfico y artífices”. En: Boletín del Museo e Instituto Camón Aznar, 114, pp. 96-97.

Esquíroz Matilla, María: "Custodia ostensorio del águila bicéfala” Colegiata de Sta. María la Mayor de Alquézar, Museo, n. cat. 600. En: Inventario de la iglesia católica II C. Aragón, n.2319, inédito.

(1994): Estudio Histórico, artístico y documental de la platería oscense, Tesis Doctoral inédita, leída en la Universidad de Zaragoza.

Exposición Iberoamericana (1929-30): Catálogo de la Sección de Arte Antiguo. Palacio Mudéjar. Sevilla: Exposición Iberoamericana.

Fajardo Rueda, Marta (1990): Oribes y plateros de Nueva Granada. Bogotá: Museo de Arte Colonial/Banco de la República.

(2009): "La orfebrería en la gobernación de Popayán”. En: Ensayos. Historia y teoría del Arte. 17, pp. 42-63.

Fernández Bayton, Gloria (1975): Inventarios reales. Testamentaría de Carlos II. T. I. Madrid: 366-367.

Fernández-Santos Ortiz-Iríbar, Jorge (2001): "Renovatio Regiae Pietatis: Reflexiones en torno al altar de la Sagrada Forma de El Escorial". En: Campos y Fernández de Sevilla, Francisco Javier (dir.): El monasterio del Escorial y la pintura. San Lorenzo de El Escorial: Real Centro Universitario EscorialMaría Cristina, pp. 643-674

García Gaínza, M ${ }^{\mathrm{a}}$ Concepción (1991): Dibujos antiguos de los plateros de Pamplona. Pamplona: Universidad de Navarra.

García Gaínza, $\mathbf{M}^{\mathrm{a}}$ Concepción/Heredia Moreno, $\mathbf{M}^{\mathrm{a}}$ Carmen/Rivas Carmona, Jesús/Orbe Sivatte, Mercedes (1980): Catálogo Monumental de Navarra I. Merindad de Tudela. Pamplona: Príncipe de Viana/Arzobispado de Pamplona/Universidad de Navarra.

Gómez Moreno, Manuel (1929): Exposición Internacional de Barcelona 1929. El Arte en España. Guía del Museo del Palacio Nacional. Barcelona: Imprenta de Eugenio Subirana.

Heredia Moreno, Carmen (1996): “Origen y difusión de la iconografía del águila bicéfala en la platería religiosa española e hispanoamericana”. En: Archivo Español de Arte, 274, pp. 183-194.

(1999): "La platería en la catedral Magistral de Alcalá de Henares". En: Morena, Áurea de la (dir.): La Catedral Magistral de Alcalá de Henares. Alcalá de Henares: Diócesis de Alcalá de Henares, pp. 139-156. 
Heredia Moreno, Carmen (2012): "Plata labrada de Indias en las flotas de Nueva España durante el reinado de Carlos II (1665-1700)". En: Montero Alarcón, Alma (coord.): Plata. Forjando México. México: Gobierno del Estado de México, pp. 63-91.

(2016): "Sobre las alhajas y el ajuar de plata de la capilla Real del Alcázar de Madrid”. En: Rivas Carmona, Jesús (coord.): Estudios de Platería. San Eloy 2016. Murcia: Universidad de Murcia, pp. 233-249.

(2018): "Precisiones, dudas e interrogantes sobre varias piezas de platería peruana en España”. En: Rivas Carmona, Jesús (coord.): Estudios de Platería. Murcia: Universidad de Murcia, pp. 245-261.

Madruga Real, Ángela (1983): Arquitectura barroca salmantina. Las Agustinas de Monterrey. Salamanca: Centro de Estudios Salmantinos.

Martín, Fernando A. (1987): Catálogo de la plata del Patrimonio Nacional. Madrid: Patrimonio Nacional.

(2015): "Don Sebastián Hurtado de Corcuera y su regalo a la Real Capi1la”. En: Rivas Carmona, Jesús (coord.): Estudios de Platería. San Eloy 2016. Murcia: Universidad de Murcia, pp. 243-251.

Martín Vaquero, Rosa (2020): "La imagen de la custodia iberoamericana en la diócesis de Vitoria: Donantes, estilos y peculiaridades". En: Salazar Simarro, Nuria/Paniagua Pérez, Jesús/Pérez Morena, Jesús (2020): El jardín de las hespérides. Estudios sobre la plata iberoamericana siglos XVI-XIX. León: Instituto de Humanismo y Tradición Clásica/México: INAH, pp. 339-365.

Maura Gamazo, Gabriel (2018): Carlos II y su Corte. Ensayo de reconstrucción biográfica. Volumen II /1669-1679). Madrid: Real Academia de la Historia.

Mediavilla O.S.A., Benito (2003): "Documentos relacionados con la Santa Forma de El Escorial”. En: Campos y Fernández de Sevilla, Francisco Javier (dir.): Religiosidad y ceremonias en torno a la eucaristía. San Lorenzo del Escorial: EDES.

Mur Ventura, Luis (1929): Genealogía de los Nasarre. Madrid: Tipografía de Archivos. Olózaga, I.

Pérez Hernández, Manuel (1990): Orfebrería religiosa en la diócesis de Salamanca ( siglos $X V$ al XIX). Salamanca: Diputación de Salamanca.

Pinelo, León (1931): Anales de Madrid desde el año 447 al de 1658. Madrid.

Portilla Vitoria, Micaela/Enciso, Emilio/Azcárate Ristori, José Ma (1988): Catálogo Monumental. Diócesis de Vitoria. T. VI. Las vertientes cántabras del noroeste alavés, la ciudad de Orduña y sus aldeas. Vitoria: Fundación Vital Fundazioa.

Rodríguez G. de Ceballos, Alfonso (1969): Estudios sobre el Barroco salmantino. El colegio Real de la Compañía de Jesús. Salamanca: Centro de Estudios Salmantinos.

Saltillo, Marqués del (1955): "Plateros madrileños (1590-1660)". En: Boletín de la Real Academia de Historia, CXXXVII, pp. 13-14. 
Samaniego Hidalgo, Santiago (1987): La platería religiosa en Fuentesaúco y comarca. Zamora.

Sebastián, Santiago (1990): El Barroco iberoamericano. Mensaje iconográfico. Madrid: Ediciones Encuentro.

Serrano Mangas, Fernando (1999): "Las flotas de la plata". En: Lopezpsa Aparicio, Concepción (coord.): El oro y la plata de las Indias en la época de los Austrias. Madrid: Fundación ICO, pp. 323-332.

Serrera, Ramón $\mathbf{M}^{\mathrm{a}}$ (1999): "Las rutas de la plata americana". En: Lopezpsa Aparicio, Concepción (coord.): El oro y la plata de las Indias en la época de los Austrias. Madrid: Fundación ICO, pp. 333-342.

Simal López, Mercedes (2017): “Óleo sobre naipe. Dos pequeños retratos de Carlos II (Según Van Kessel II) y Mariana de Neoburgo del Museo Nacional de Artes Decorativas". En: Además de. Revista on line de artes decorativas y diseño, 3, pp. 29-52.

Sigaut, Nelly (2017): "Las custodias del águila bicéfala". En Libros de la Corte.es, 15, pp. 70-92. https://doi.org/10.15366/ldc2017.9.15.004. (18-3-2020).

Stepánek, Pavel (1990): "Dos bocetos para la Sagrada Forma de Claudio Coello, en Praga”. En: Reales Sitios, 103, pp. 30-36.

Valencia de Redondo, M ${ }^{\mathrm{a}}$ Eugenia (1992): "Custodia de águila bicéfala". En Castañeda Delgado, Paulino (coord.): La Iglesia en América. Evangelización y cultura. Pabellón de la Santa Sede. Exposición Universal. Sevilla: Anaya, p. 325.

Ximénez, Fr. Andrés (1764): Descripción del Real Monasterio de San Lorenzo de El Escorial. Madrid. 


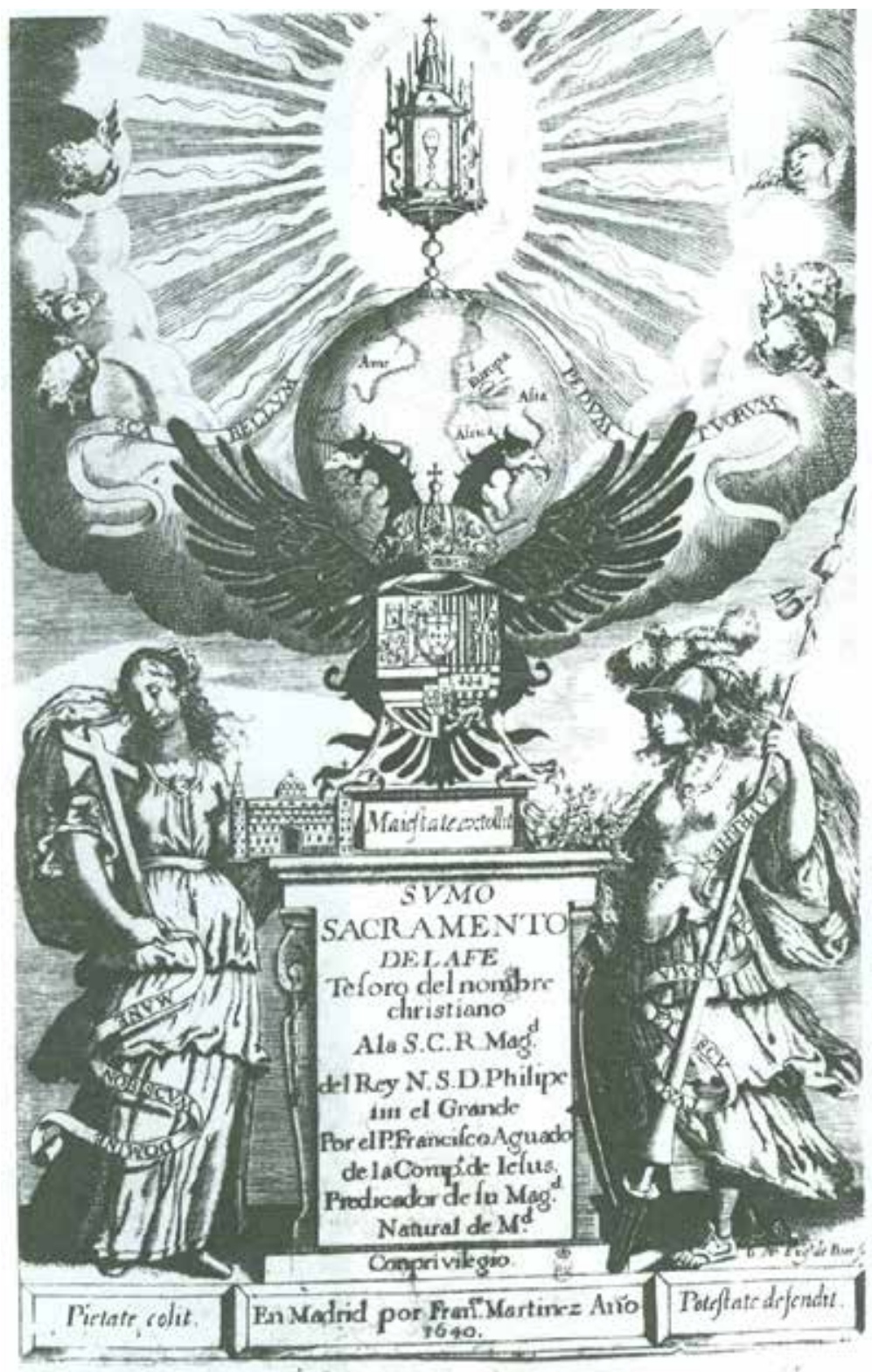

Figura 1. M $\mathrm{M}^{\mathrm{a}}$ Eugenia Beer, portada del Sumo Sacramento de la Fe, 1640. Foto reproducida en Heredia Moreno, 1996: 190. 


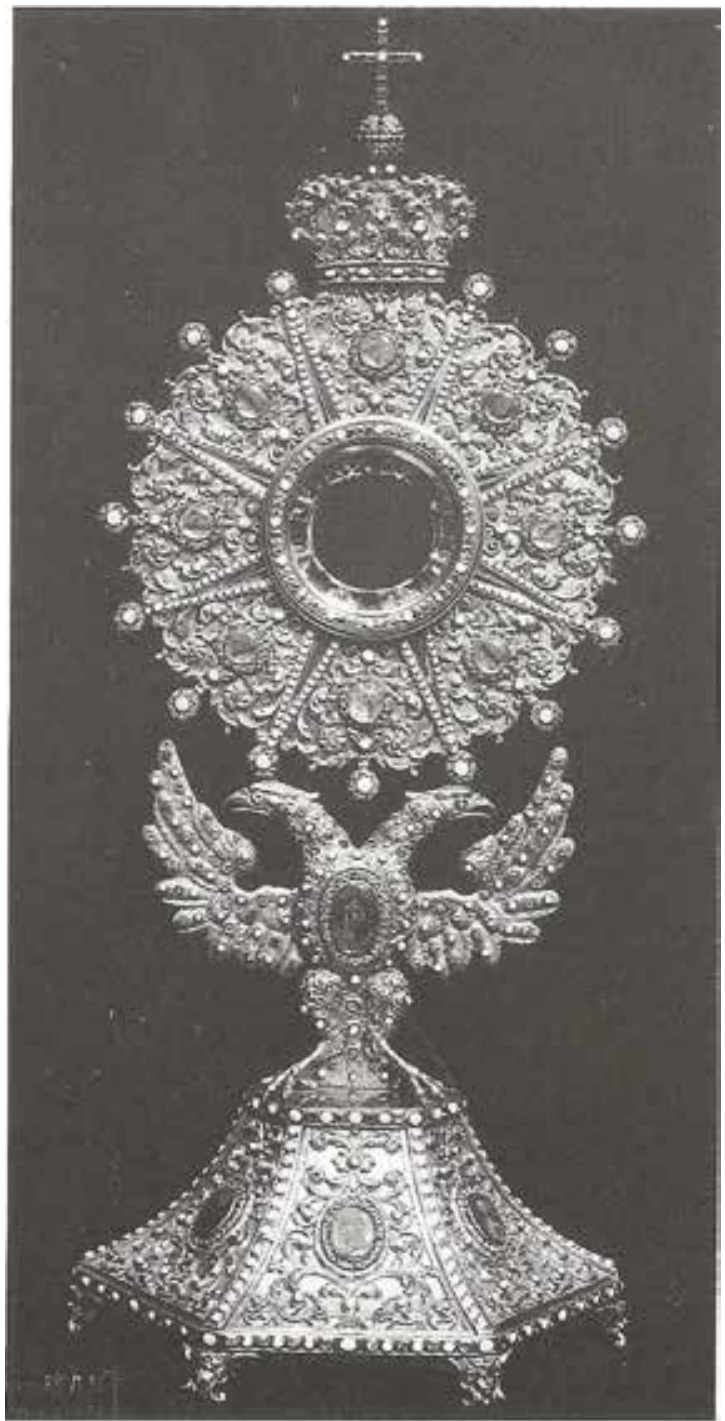

Figura 2. Francesco Filippini, Custodia, entre 1678-1694, Convento de Agustinas de Salamanca. Foto: Archivo Fotográfico del CSIC, núm. 39322. 


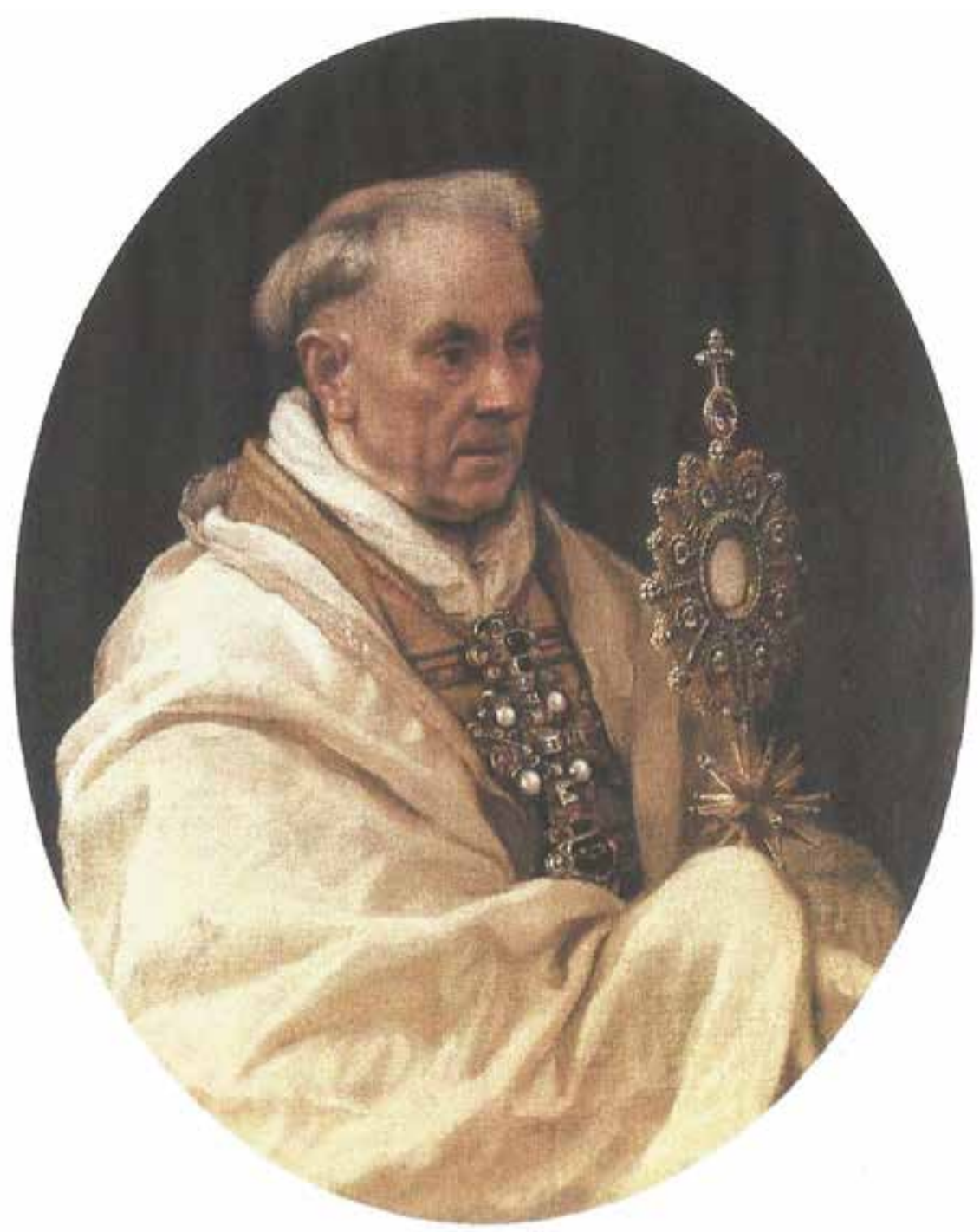

Figura 3. Claudio Coello, Retrato del Padre Francisco de los Santos, 1685-1689, Praga, Narodin Galerie. Foto reproducida en Stepánek, 1990:33. 


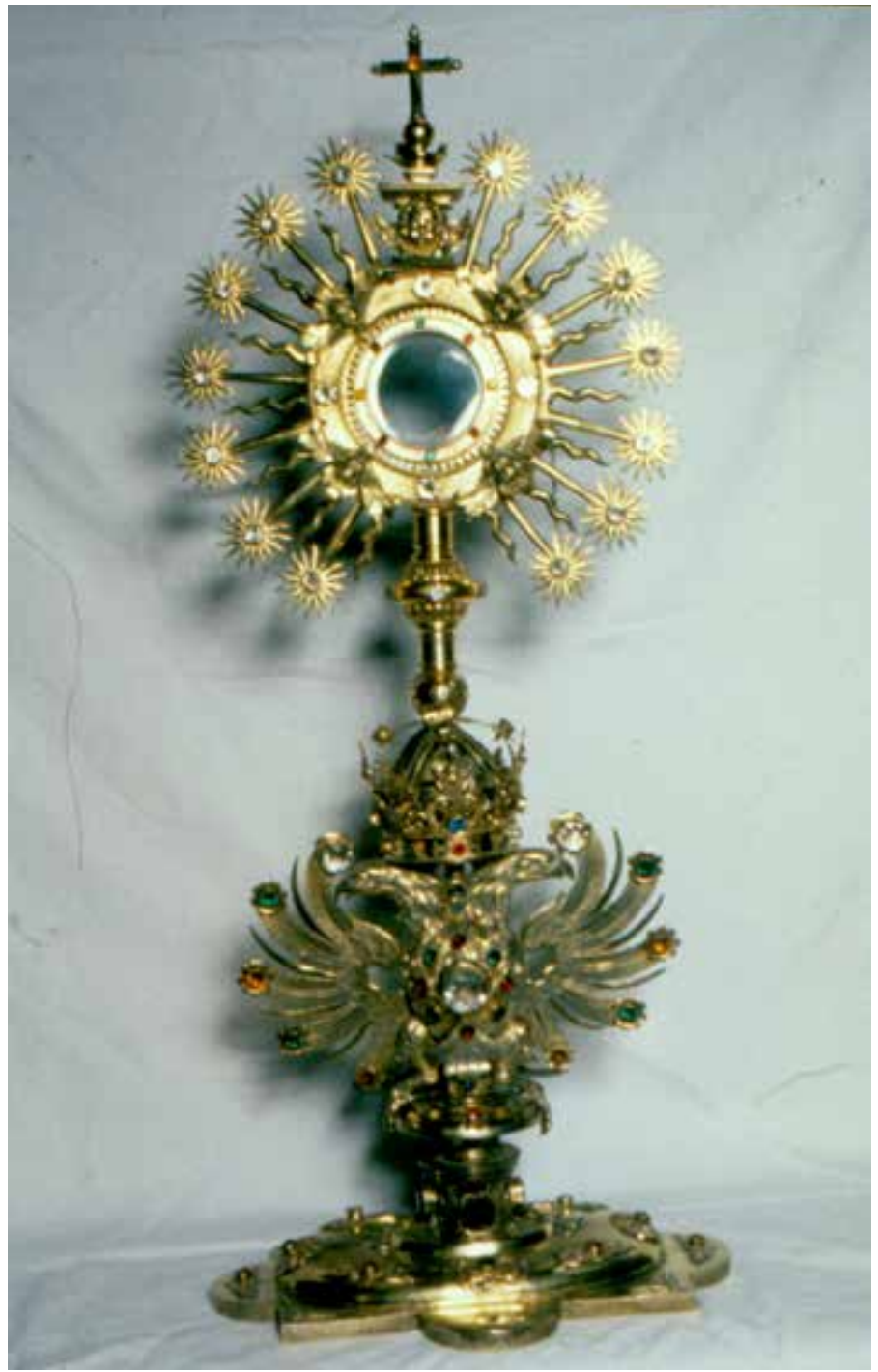

Figura 4. Rafael González Sobera,

Custodia, 1683, Santa María de Orduña. Foto: Pedro Echeverría. 


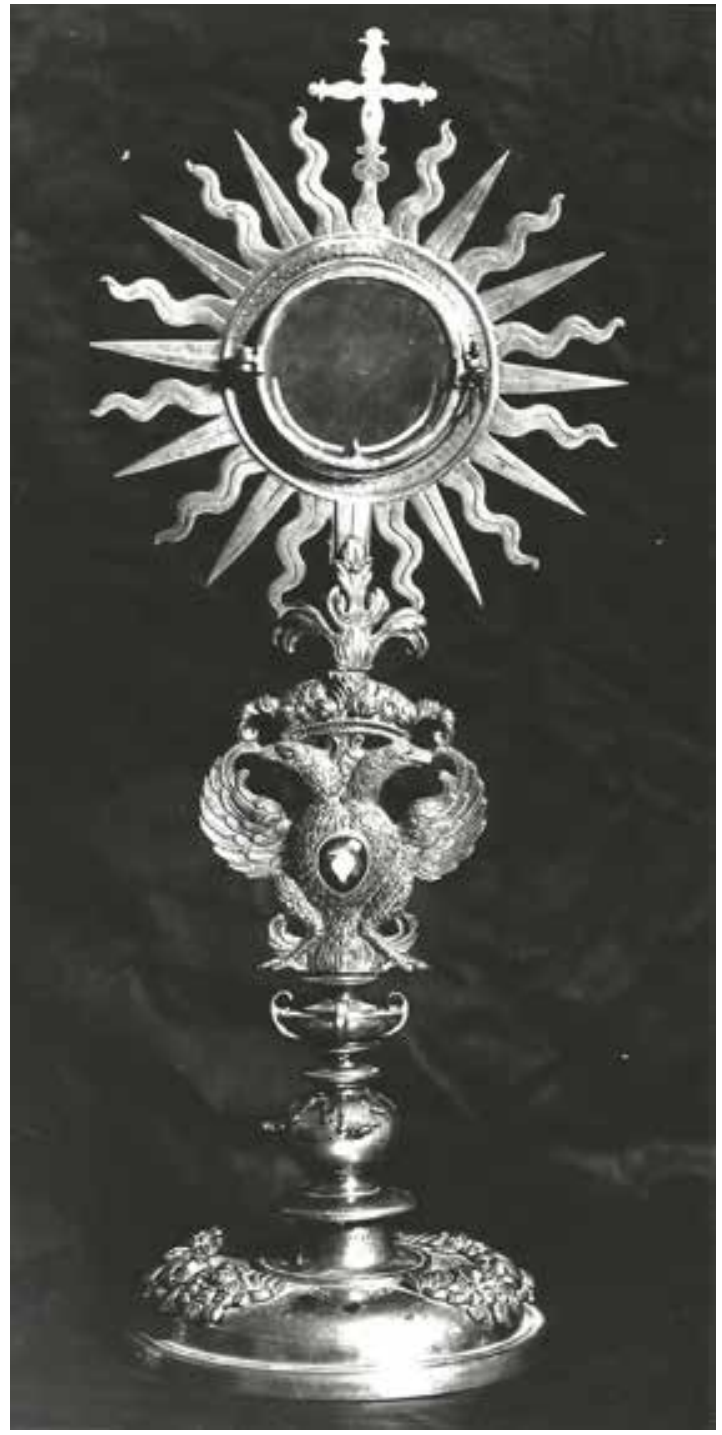

Figura 5. Anónimo madrileño, Custodia, c. 1680, Santa María del Castillo de Alquézar (Huesca), Foto "Arxiu Mas", c.18614. 


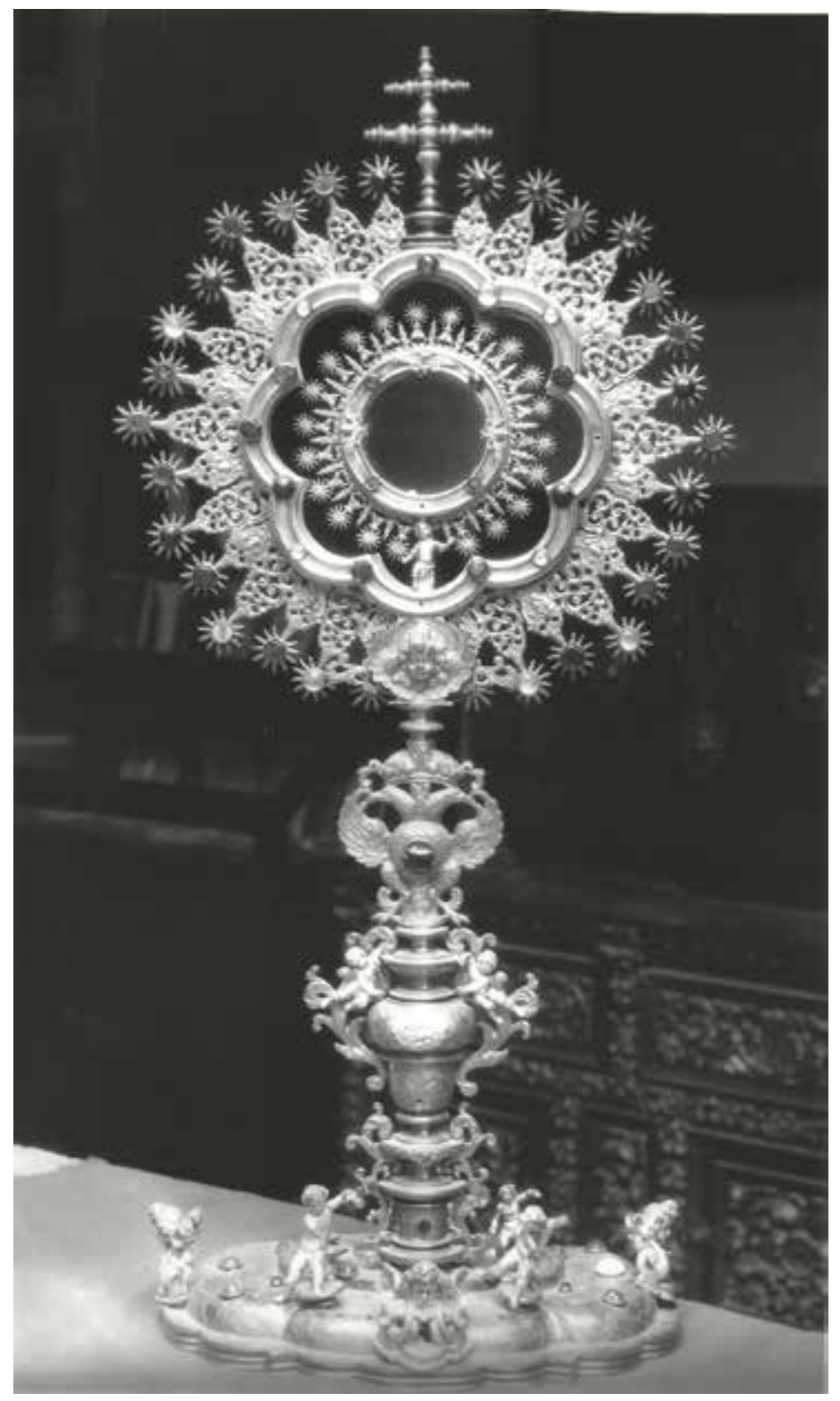

Figura 6. Círculo de Cristóbal de Alfaro, Custodia, c. 1712, cabildo catedral de Madrid (paradero desconocido). Foto "Arxiu Mas", c.57870. 


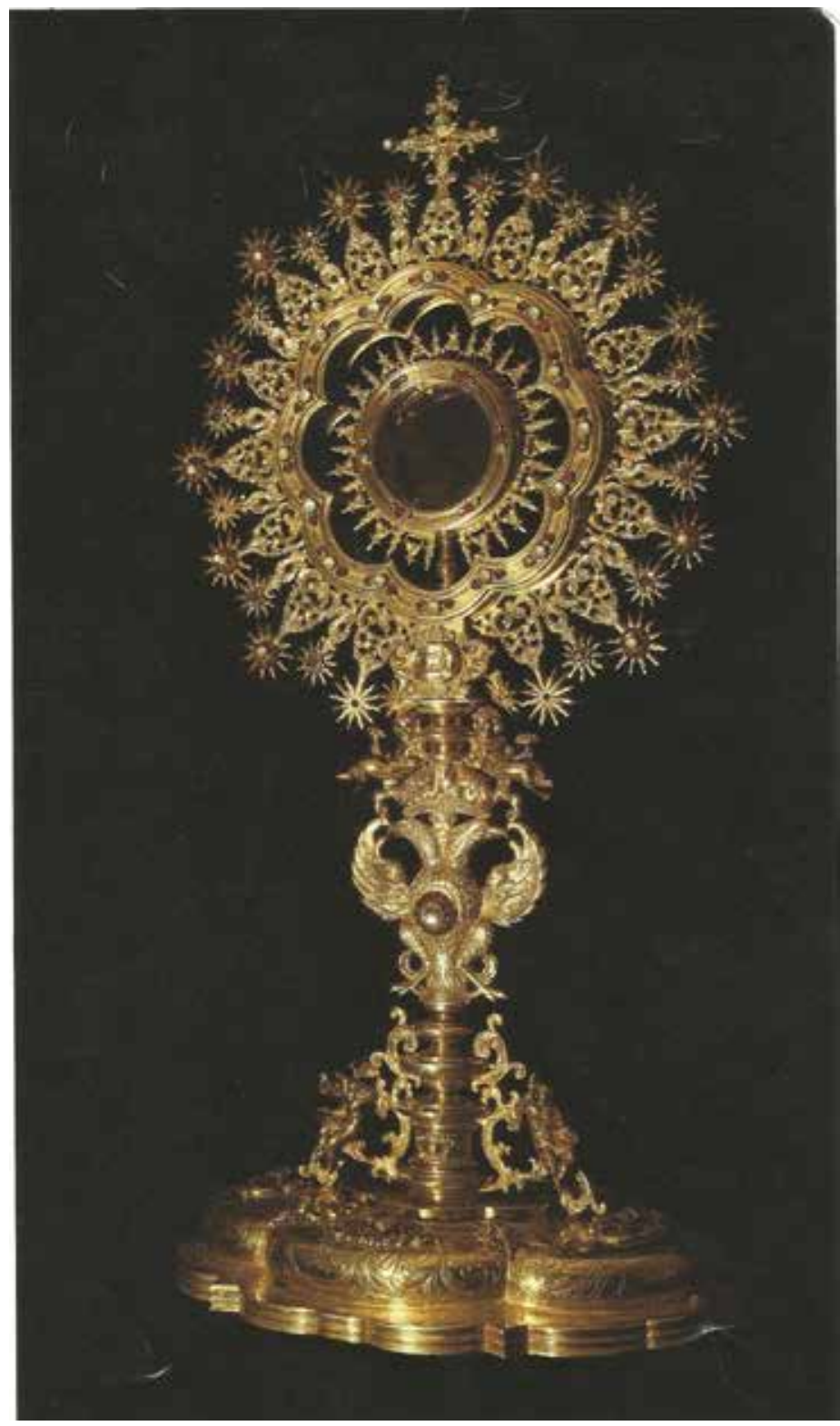

Figura 7. Cristóbal de Alfaro, custodia, 1699, Santa María de Valtierra. Foto: Carmen Heredia. 


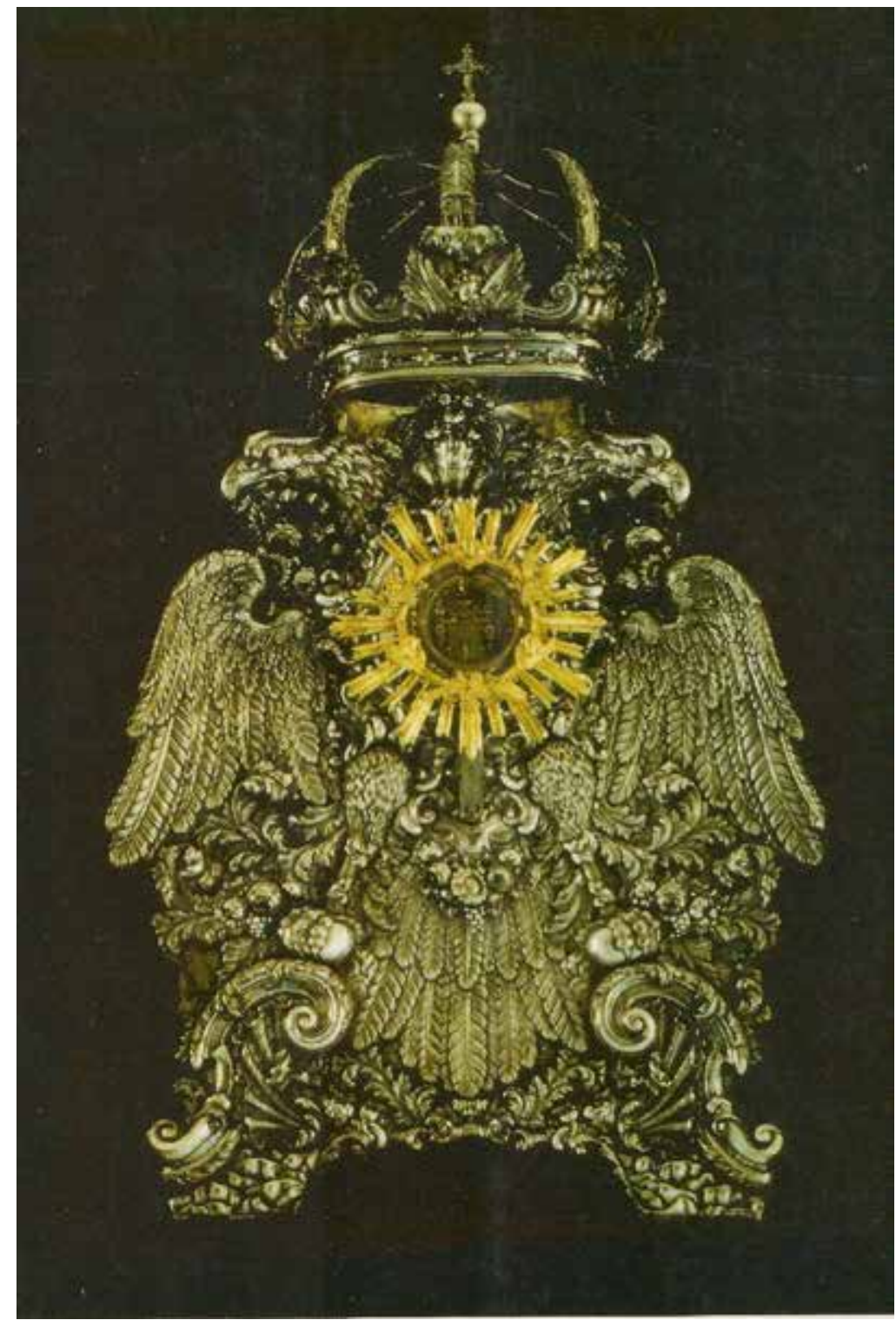

Figura 8. Luis García Crespo, custodia, c. 1750, Museo Diocesano de Salamanca.

Foto reproducida en Pérez Hernández, 1990. 